OPEN ACCESS

Edited by:

Ziad Mallat,

University of Cambridge,

United Kingdom

Reviewed by:

Sumanth D. Prabhu,

University of Alabama at Birmingham,

United States

Hendrik B. Sager,

Deutsches Herzzentrum München,

Germany

${ }^{*}$ Correspondence:

Edward B. Thorp

ebthorp@northwestern.edu

${ }^{\dagger}$ Co-first authors

Specialty section:

This article was submitted to

Cardiovascular Biologics and

Regenerative Medicine,

a section of the journal

Frontiers in Cardiovascular Medicine

Received: 17 November 2018 Accepted: 22 March 2019

Published: 11 April 2019

Citation:

Zhang S, Bories G, Lantz C

Emmons R, Becker A, Liu E, Abecassis MM, Yvan-Charvet $L$ and Thorp EB (2019) Immunometabolism of Phagocytes and Relationships to

Cardiac Repair.

Front. Cardiovasc. Med. 6:42. doi: 10.3389/fcvm.2019.00042

\section{Immunometabolism of Phagocytes and Relationships to Cardiac Repair}

\author{
Shuang Zhang ${ }^{1 \dagger}$, Gael Bories ${ }^{2 \dagger}$, Connor Lantz ${ }^{1}$, Russel Emmons ${ }^{1}$, Amanda Becker ${ }^{3}$, \\ Esther Liu ${ }^{1}$, Michael M. Abecassis ${ }^{4}$, Laurent Yvan-Charvet ${ }^{2}$ and Edward B. Thorp ${ }^{1 *}$ \\ ${ }^{1}$ Departments of Pathology and Pediatrics, Feinberg Cardiovascular and Renal Research Institute, Feinberg School of \\ Medicine, Northwestern University, Chicago, IL, United States, ${ }^{2}$ UMR INSERM U1065/UNS, C3M, Bâtiment Universitaire \\ ARCHIMED, Nice, France, ${ }^{3}$ Department of Pediatrics, Ann \& Robert H. Lurie Children's Hospital of Chicago, Northwestern \\ University, Chicago, IL, United States, ${ }^{4}$ Comprehensive Transplant Center, Northwestern Feinberg School of Medicine, \\ Chicago, IL, United States
}

Cardiovascular disease remains the leading cause of death worldwide. Myocardial ischemia is a major contributor to cardiovascular morbidity and mortality. In the case of acute myocardial infarction, subsequent cardiac repair relies upon the acute, and coordinated response to injury by innate myeloid phagocytes. This includes neutrophils, monocytes, macrophage subsets, and immature dendritic cells. Phagocytes function to remove necrotic cardiomyocytes, apoptotic inflammatory cells, and to remodel extracellular matrix. These innate immune cells also secrete cytokines and growth factors that promote tissue replacement through fibrosis and angiogenesis. Within the injured myocardium, macrophages polarize from pro-inflammatory to inflammation-resolving phenotypes. At the core of this functional plasticity is cellular metabolism, which has gained an appreciation for its integration with phagocyte function and remodeling of the transcriptional and epigenetic landscape. Immunometabolic rewiring is particularly relevant after ischemia and clinical reperfusion given the rapidly changing oxygen and metabolic milieu. Hypoxia reduces mitochondrial oxidative phosphorylation and leads to increased reliance on glycolysis, which can support biosynthesis of pro-inflammatory cytokines. Reoxygenation is permissive for shifts back to mitochondrial metabolism and fatty acid oxidation and this is ultimately linked to pro-reparative macrophage polarization. Improved understanding of mechanisms that regulate metabolic adaptations holds the potential to identify new metabolite targets and strategies to reduce cardiac damage through nutrient signaling.

Keywords: macrophage, neutrophil, phagocyte, immunometabolism, hypoxia, reperfusion, cardiac repair

\section{INTRODUCTION}

According to the American Heart Association, 720,000 individuals in the United States alone will succumb to a first hospitalized acute myocardial infarction (AMI), and $\sim 335,000$ more will have a recurrent event (1). Improvements in timeliness and efficiency of clinical treatment have reduced mortality after first heart attack. Nevertheless, the incidence of heart failure, including post-MI heart failure, has seen recent escalations (2). The progression to heart failure is often related to the degree of ventricular damage after acute insult. Occlusion of coronary arteries restricts blood flow to the myocardium. This leads to reduced oxygen availability and metabolic substrates that are essential to sustain active cardiomyocyte metabolism. Oxygen restriction also 
modulates the immune response to the injured heart. Further clinical percutaneous reperfusion and re-oxygenation may cause unintended tissue damage in the ischemic heart (3).

Acute Coronary Syndromes Have Long Been Associated With Inflammation $(4,5)$ and Metabolic Syndromes. In the majority of patients who succumb to sudden death after AMI, cardiac pathology typically reveals significant accumulation of polymorphonuclear and mononuclear phagocytes. In general, acute inflammation is followed by a resolution program that acts to dampen the amplitude of inflammation and orchestrate tissue repair. However, in many diseases of aging, this transition fails and leads to a persistence of chronic inflammation (6). Defects in inflammation resolution are often linked to a systemic metabolic imbalance (7). A similar phenomenon may occur after AMI, in which inefficient inflammation resolution due to hyperlipidemia (8) is linked to maladaptive myeloid response (9). In experimental animals, the ischemic heart recruits a diverse repertoire of innate and adaptive immune cells. This is triggered by chemokines and cytokines that are secreted by cardiac resident and recruited cells. Neutrophils enter and accumulate in the ischemic heart soon after AMI, and this is followed by recruitment of monocyte subsets. Two monocyte sources are of particular interest in this context. This includes monocytes generated from hematopoietic stem cells in the bone marrow, and mature monocytes released from the splenic reservoir (10). Independent of their site of origin, these monocytes differentiate into cardiac macrophages (11), which may either contribute to promote or resolve the inflammatory response (11). This occurs by the liberation of cytokines and growth factors that are recognized by parenchymal and stromal cells and therefore modulate the tissue response to injury (12).

Within the ischemic myocardium, reductions in both oxygen and nutrient supply are associated with acute cell death and necrosis (13). Prolonged ischemia impairs mitochondrial oxidative phosphorylation that is coupled to the synthesis of adenosine triphosphate (ATP) synthesis. In order to meet bioenergetic demands needs, cells must then rely on glycolysis, which in turn increases the concentration of lactate. Intracellular lactate accumulation lowers cytosolic $\mathrm{pH}$ whereas extracellular lactate is sensed by immune cells and can lead to their activation (14). Accumulation of metabolically active immune cells also depletes local oxygen and nutrient substrate availability. A consequence of reduced oxygen availability is the induction of hypoxia-inducible transcription factors (HIF), which act transcriptionally to promote glycolysis. Additional triggers, including liberation of damage associated molecular patterns (DAMP) in heart (15), activate immune cell toll like receptors, that are also tied to signaling that induce glycolytic polarization. This glycolytic switch has functional consequences. This includes facilitating the diversion of metabolites from Krebs cycle and the pentose phosphate pathway (PPP), to substrates that promote cellular proliferation during tissue repair. As the repair site matures, macrophages polarize to phenotypes associated with mitochondrial oxidative phosphorylation, as discussed below. Most studies of myocardial ischemic metabolism have focused on the myocyte. In contrast, discussed herein (Figures 1, 2) are advancements in the field of immunometabolism that hint at a significant role of phagocyte metabolism to cardiac repair.

\section{NEUTROPHIL IMMUNOMETABOLIC LINKS TO HEART}

As the predominant phagocyte in blood, the glycolytic-biased polymorpho-nuclear (PMN) neutrophil, is primed to rapidly respond to secreted alarms of tissue injury (16). PMNs have been referred to as the "wrecking crew" for their propensity to secrete proteases that facilitate wound breakdown that enables wound clearance. Thus, PMNs contribute to reparative functions after tissue injury, however they are also notoriously affiliated with causing maladaptive collateral tissue damage, particularly after clinical reperfusion. Patients in the highest tertile of circulating neutrophils track with heightened risk for MI (17). This bad reputation extends to after cardiac transplant, as pre-operative neutrophil phenotype is a biomarker for early allograft rejection (18). Elevated neutrophils are also prognostic for poor clinical outcome (19) and directly correlate with infarct size following percutaneous coronary intervention (20). Neutrophil depletion and inhibition of neutrophil-derived enzymes (21) have long been associated with experimental improvements with cardiac function (22). Harmful neutrophil effects may be amplified in the setting of metabolic syndromes (23). For example, neutrophils from hyperlipidemic patients exhibit elevated markers of superoxide release (24). Moreover, neutrophils from diabetic humans and experimental mice are more susceptible to cell death by NETosis (neutrophil extracellular traps), which impairs wound healing (25) and is linked to glucose metabolism. In contrast, neutrophil depletion may aggravate cardiac function after AMI, which is consistent with a conserved reparative function (26). The mechanism underlying this protective role may be linked to crosstalk with macrophages, which can polarize toward a reparative phenotype after PMN efferocytosis. This dichotomy between deleterious vs. protective roles of PMNs after AMI may be better understood by examining PMN function at distinct stages of AMI inflammation vs. resolution vs. reperfusion, as further discussed below.

\section{Recent Reports Highlight our Evolving Understanding of Neutrophil Polarity (16)}

For instance, neutrophils isolated from infarcted mouse hearts on the first days after coronary ligation expressed proinflammatory markers IL $1 \beta$ and TNF $\alpha$. By contrast, the neutrophil profile was more anti-inflammatory a few days later (27). In tumors, neutrophils have been classified into N1 and N2 polarization states (28), akin to the widely but overly simplistic M1/M2 macrophage classification. In this context, it is tempting to speculate that neutrophil polarization states may reflect unique metabolic rewiring, as illustrated in the M1/M2 dichotomy. 


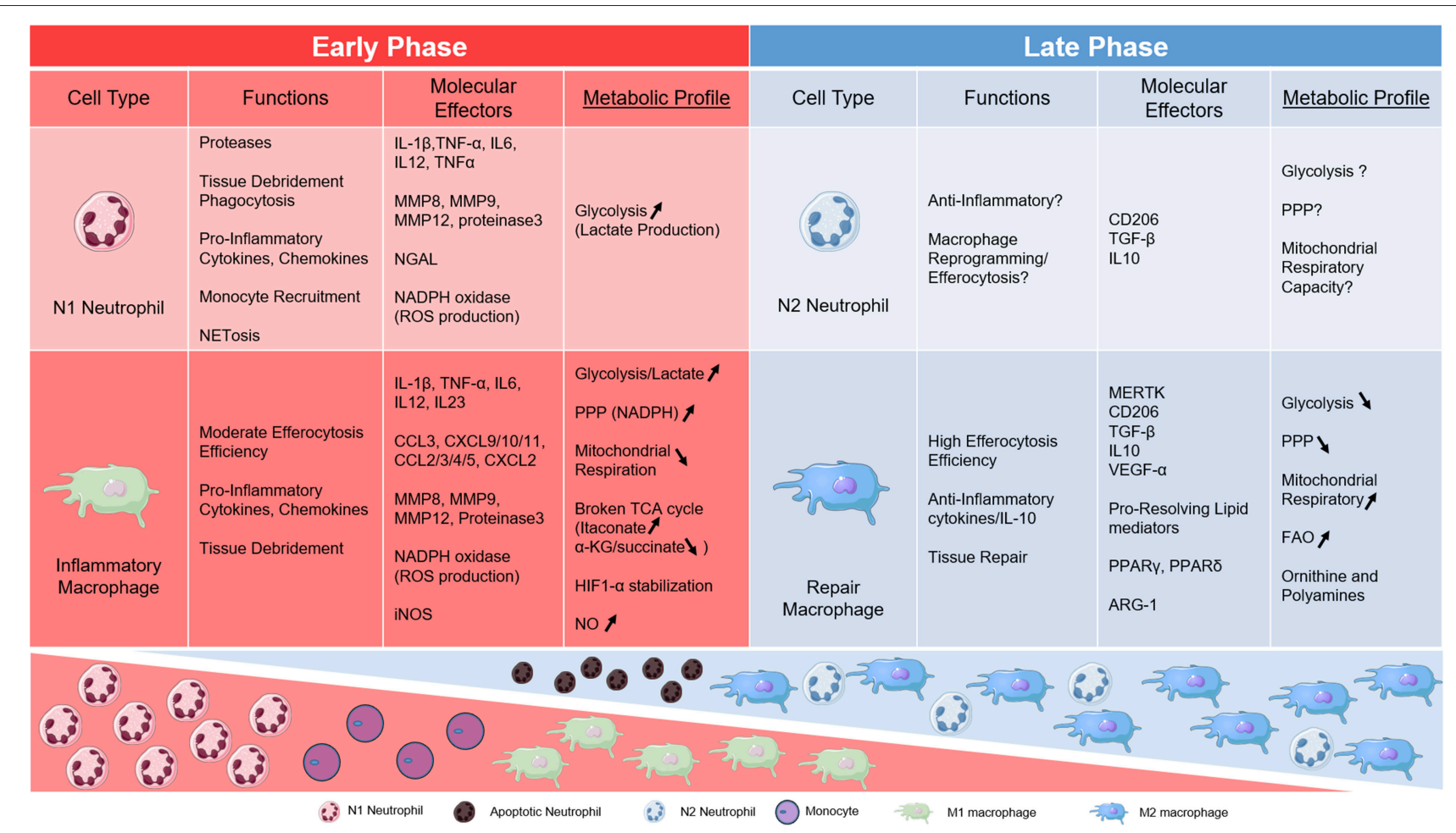

FIGURE 1 | Table of metabolic links to key phagocytes during AMI. Neutrophil and Macrophage subsets are divided into early and late phases of cardiac inflammation after myocardial infarction and according to metabolic phenotype.

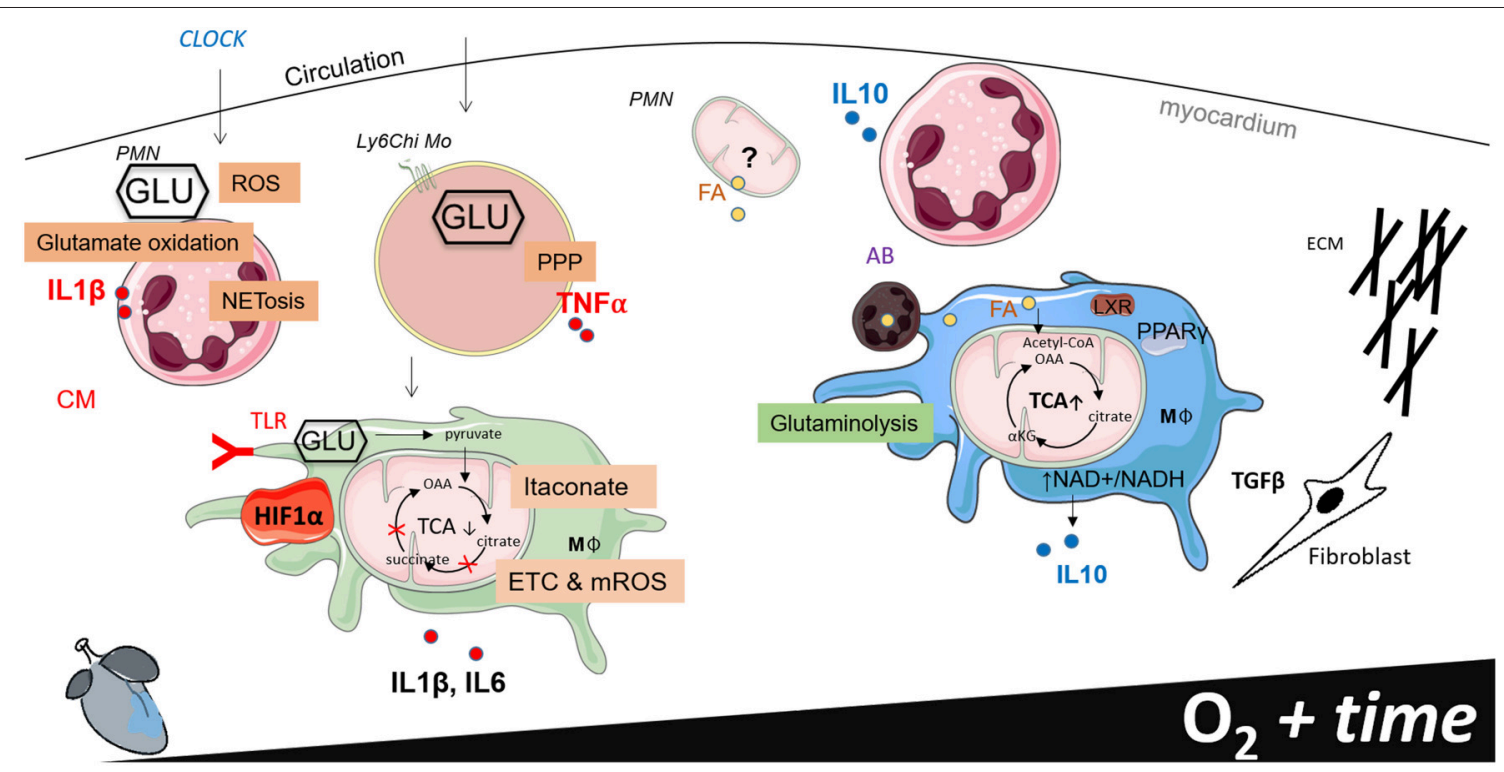

FIGURE 2 | Working model of phagocyte immunometabolism after myocardial infarction (MI). This figure separates cardiac inflammation based on time (the first week post MI) and oxygen saturation within the infarct border zone. Little information is known about the functional metabolic capacity of macrophage CCR2 and MHCII resident and recruited subsets in the heart, therefore generalizations are made to classify macrophages according to metabolic phenotype.

Neutrophil variation also manifests through diurnal variation. For example, immune regulation may be tied to a metabolic clock (29). It has been estimated that $\sim 15 \%$ of all metabolites may be under circadian control (30). This includes amino acid, lipid, and carbohydrate metabolic pathways (31). A molecular clock may integrate daily metabolic changes driven 
by feeding-fasting and energy storage, to immune function. Indeed, the master inflammatory regulator $\mathrm{NF \kappa B}$ is required for maintenance of behavioral rhythm in mice (32). Among immune cells, neutrophils appear unique in their daily pattern of release, re-entry, and clearance from the bone marrow (33). In this context, neutrophil recruitment to sites of tissue injury is altered by time of day. In heart, elevations in chemokinedependent recruitment of neutrophils occurred during nonsleep activity periods, relative to rest. During cardiac injury, heightened cardiac neutrophil infiltration was also observed during these activity periods (34). This was in parallel to systemic metabolic fluctuations in hepatic gluconeogenesis, elevated serum glucose (35), and leukocyte mobilization from the bone marrow (36). Nevertheless, it remains unclear if rhythmic neutrophil recruitment is also associated with neutrophil metabolic and inflammatory polarization. Although causal molecular clock mechanisms in neutrophils have not been characterized in detail, clock genes such as Bmall exhibit significant daily variation in human neutrophils. Furthermore, human peripheral neutrophil pools display daily oscillation that correlates with time-dependent changes in superoxide production and phagocytosis (37). Circadian clock also controls the activity of the NAD+ dependent deacetylase Sirtuin3, which dampens mitochondrial respiration and oxidative enzyme activity (38). Interestingly, Sirtuin 3 deficiency aggravates experimental thrombosis and leads to increased neutrophil extracellular traps (NET). Taken together, intriguing links between circadian rhythm, neutrophil function, and metabolism are brought to light (39).

\section{Recent Findings Implicate Mitochondrial Respiration Pathways in Neutrophil Maturation}

For example, autophagy-dependent generation of fatty acids is important during neutrophil differentiation. Autophagy-defective neutrophil precursors have increased glycolytic activity but impaired mitochondrial respiration and fatty acid oxidation. This led to lipid droplet accumulation and diminished neutrophil development (40). These data suggest that autophagy is necessary for the release of free fatty acids from intracellular stores and within neutrophil precursor cells. That is, lipophagy may be required to provide mitochondrial fuel to support oxidative phosphorylation necessary for neutrophil maturation. On the other hand, mice lacking autophagy related 5 (Atg5), a gene essential for autophagosome formation, exhibited increased neutrophil proliferation and maturation (41). Furthermore, treatment of myeloid progenitors with ATP-synthase inhibitor oliogomycin, reduced electron transport chain flow and neutrophil differentiation, highlighting the essential role of oxidative phosphorylation during neutrophil maturation (42). Finally, mitochondrial dysfunction has been associated with an impaired unfolded protein stress response and mitochondrial dysfunction, leading to reduced neutrophil differentiation $(43,44)$. The contribution of most of these pathways in heart are largely untested.

\section{As Early as the 1960s, Observations Were Made in Guinea Pigs, Reporting That Mature Polymorphonuclear Leukocytes Are Glycolytic (45)}

This is consistent with ultrastructural imaging, which often fails to identify significant numbers of mitochondria in mature neutrophils (46). Furthermore, mitochondrial respiration in neutrophils was found to be low (47). These observations have led to a hypothesis of high glycolytic reliance and a selective role of the mitochondria as a platform for apoptotic signaling $(47,48)$. Indeed, neutrophils rely greatly on glycolysis for their inflammatory functions (48). Glycolysis is increased in neutrophils during phagocytosis, and in the absence of glucose, the rate of ATP generation in neutrophils drops drastically. Furthermore, neutrophils from patients with chronic granulomatous disease have the same rate of glycolysis and ATP content as normal cells, consistent with resistance to defective respiration with glycolytic bias (49). After release, NETs become crosslinked to plasma fibrinogen, leading to thrombosis. This is a reason for the "no-reflow" phenomenon observed when artery circulation is restored. Thus, an experimental treatment approach employing DNase-based and thrombolytic agent combinations to treat ischemia-reperfusion injury has been shown to reduce NET formation and result in long-term benefit in heart function (50). NETs have also been identified in patients with ST-elevation myocardial infarction (STEMI) (51). Glycolysis and the glucose transporter (Glut-1) have also been implicated in NET formation (52). The pentose phosphate pathway (PPP) is also critical for NET release. Glucose diversion toward the PPP allows the production of nicotinamide adenine dinucleotide phosphate (NADPH), which in turn fuels NADPH oxidase to produce superoxide, and NETs release (53).

\section{In Addition to Their Pro-Inflammatory Roles, Neutrophils and Their Metabolism Also Play a Role in Inflammation Resolution}

For example, neutrophils metabolize the specialized proresolving lipid Resolvin E1 (RvE1), derived from omega-3 eicosapentaenoic acid, into inactive byproducts. This may be part of a coordinated return to homeostasis as RvE1 is a proresolving lipid mediator that is pro-phagocytic at low $\mathrm{nM}$ concentrations (54). Neutrophils at steady state also facilitate a diurnal IL-23 signaling axis to alert the need for additional myeloid cells (55). During inflammation, neutrophils recruit inflammatory monocytes and macrophages (56). Inflammatory neutrophils secrete chemoattractants such as heparin binding protein (HBP) (57) and LL-37 (58) that regulate monocyte and macrophage infiltration. In heart, neutrophils trigger macrophage polarization toward an anti-inflammatory and a reparative phenotype (26), whereas depleting neutrophils with monoclonal Ly-6g antibodies in mice inhibited Ly6 Chi monocyte release from splenic reservoirs. This in turn increased macrophage proliferation in the infarct, and increased cardiomyocyte death, fibrosis, and markers of heart failure. An 
interesting question to answer is whether neutrophils may also instruct cardiac macrophage reprogramming through rewired cellular metabolism. Phagocytic uptake of dying neutrophils and apoptotic cells is known to induce an anti-inflammatory response. The phagocytic program is regulated by nuclear receptors including LXR (59), PPAR $\gamma$ (60), and PPAR $\delta$, which are known to be master-regulators of lipid and mitochondrial metabolism (61).

\section{MACROPHAGE METABOLISM AND LINKS TO CARDIAC REPAIR}

\section{For Decades we Have Appreciated That Activated Macrophages Often Exhibit Features of Heightened Glycolysis and Warburg Metabolism (62)}

This phenotype is characterized by augmented glycolysis, increased expression of glycolytic enzymes (63), and diminished oxygen consumption. Although a less efficient path for the generation of ATP, glycolysis does not requires oxygen, which is rate limiting during myocardial hypoxia. Oxygen reductions stabilize macrophage HIFs (64) and accumulation of the HIF- $1 \alpha$ isoform is linked to glycolytic induction, including glucose transporter GLUT-1 (65), hexokinase (66), and 6phosphofructokinase (67). Simultaneously, HIF-1 $\alpha$ may antagonize oxidative phosphorylation by shunting pyruvate away from the mitochondria through the action of PDK1 (68). Interestingly, HIFs also sense changes in metabolism from extracellular sources. For example, lactic acid produced by glycolytic tumor cells, induces a HIF- $1 \alpha$-dependent polarization of tumor-associated macrophages (69). In macrophages, metabolic regulation by HIFs appears to be a property specific to the HIF- $1 \alpha$ isoform. HIF- $2 \alpha$ in contrast induces inflammatory cytokines, independent of significant changes in glycolysis (70). During myocardial infarction, Hif- $1 \alpha$ deficiency in myeloid cells decreased leukocyte recruitment inside the damaged tissue and improved cardiac function post MI (71). Glycolysis and HIFs are also triggered by the activation of macrophage toll like receptors (72). In heart, liberation of endogenous damage-associated molecular patterns (DAMPs) become ligands for TLR activation (73). TLR4-activation stimulates glycolysis and triggers pyruvate kinase-M2, in cooperation with HIF- $1 \alpha$ and to transactivate the expression of the Il1 $\beta$ gene (74). As discussed further below, HIF- $1 \alpha$ is activated after TLR4 stimulation through the accumulation of TCA-derived succinate (75). Under aerobic conditions, AKT-mTOR signaling activates HIF- $1 \alpha$ to "train" immunity (76) through epigenetic remodeling. Trained immune cells are also characterized by a high ratio of nicotinamide adenine dinucleotide $(\mathrm{NAD}+)$ relative to its reduced form $\mathrm{NADH}$. NAD + has been implicated in key macrophage signaling events. For example, NAD+ depletion can induce macrophage necroptosis while NAD+ replenishment protects cell from necroptosis and alleviates cytotoxicity (77). In a therapeutic context, intraperitoneal injection of NAD precursor nicotinamide mononucleotide (NMN) significantly increased $\mathrm{NAD}+$ in heart and protected from I/R injury (78).

The propensity for glycolytic activation in innate immune cells during inflammation is exploited in the clinic. For example, glucose analog 2-(18F)-fluoro-2-deoxy-D-glucose (FDG) concentrates in tissue with high glycolytic activity (79), including organs rich in inflammatory macrophages (80); this is readily detected by positron emission tomography. Granulocyte-macrophage colony-stimulating factor (GM-CSF), which attracts phagocytes to the heart (81), enhances macrophage glycolytic activity and 18F-FDG-update during inflammation in vivo (82), and after MI (83). More recent approaches have noninvasively imaged glycolytic cardiac inflammation with hyperpolarized magnetic resonance through employ of [1${ }^{13} \mathrm{C}$ ] pyruvate and lactate (84). Development of similar clinical techniques to monitor the balance between immune cell glycolysis and oxidative phosphorylation may be useful in differentiating discreet stages of inflammation and inflammation resolution.

\section{The PPP}

The switch to glycolysis from oxidative phosphorylation is more efficient for the generation of biosynthetic intermediates that may fuel macrophages in the response to tissue injury. This is in part due to the pentose phosphate pathway (PPP), or hexose monophosphate shunt. Increased glycolytic utilization drives buildup of metabolites like glucose-6-phosphate, which flux into the PPP. This shunt is an alternative glucose-oxidizing pathway that is essential for the production of purines and pyrimidines for nucleic acid synthesis. The PPP also produces NADPH through Glucose-6-phosphate dehydrogenase (G6PD) and phosphogluconate dehydrogenase (PGD). NADPH is fed into NADPH oxidase and NOX2 on phagosomes $(85,86)$ to generate localized reactive oxygen species; this may also be useful for the breakdown of engulfed apoptotic bodies during transport to the lysosome. NADPH is additionally important during lightchain 3 associated phagocytosis (87). Thus, the PPP may serve as an important metabolic shunt in phagocytes during early phagocytic phases of MI. Interestingly, metabolite profiling of blood from patients undergoing planned MI, revealed a signature that included alterations in the PPP (88). Due to its dual role, the PPP is also essential to protect macrophages against oxidation by fueling with numerous NADPH-dependent antioxidative enzymes as glutathione-disulfide reductase (89). In the case of excess of circulating glucose, as in diabetic patients, G6PD, a ratelimiting enzyme of the PPP, may be reduced. This can elevate oxidative stress and cell death susceptibility (90). Hyperglycemia promotes myelopoiesis, increases circulating neutrophils, and impairs inflammation resolution in atherosclerosis (91). Elevated myelopoiesis is also a risk factor for impaired cardiac healing post MI (92). Moreover, hyperglycemia leads to increased advanced glycation end products and inflammatory macrophage RAGE signaling (93); this may be targeted by RAGE antagonists (93). The consequences of insulin resistance on macrophage immunometabolic function requires further study. 


\section{Glycolytic Pathways Also Feed Into the Mitochondria}

Beyond their energetic function, mitochondria act as signaling organelles (94). This was prominently exemplified by the discovery that mitochondrial cytochrome $\mathrm{c}$ is released into the cytosol to activate cell death signaling (95). Mitochondria also release metabolites and reactive oxygen species (96) which activate cytosolic signaling. Signaling complexes may also form on outer mitochondrial membranes and form connections with the endoplasmic reticulum as mitochondria-associated membranes and transport lipids between organelles (97).

In the case of inflammation, toll like receptor signaling triggers re-localization of mitochondria to sites proximal to phagosomes. This subcellular trafficking augments the production of mitochondrial reactive oxygen species (ROS) (98).

ROS is also generated by the mitochondrial electron transport chain/ETC. The ETC is composed of four respiratory complexes. Complex I, III, and IV have been found to assemble as larger molecular super-complexes (99). Interestingly, TLR signaling and inflammasome NLRP3 activation reduce the formation of these super-complexes, in turn leading to increased CII activity. The adaptation of ETC complex assembly, including CII activity, is linked to macrophage activation (100). The ETC is also tightly coupled to the TCA. During inflammation, integrated metabolomics and transcriptomics analyses have revealed TCA cycle breaks. For example, one disruption occurs at isocitrate dehydrogenase (IDH) (101). This IDH break leads to the escalation of itaconate (102), which is highly produced by activated macrophages (103). Itaconate in activated macrophages inhibits dehydrogenase-mediated oxidation of succinate and is anti-inflammatory in culture as well as after myocardial ischemia-reperfusion injury (102). As introduced above, a second inflammation-induced TCA break may occur at succinate (101). Succinate is linked to macrophage activation through the activity of succinate dehydrogenase (104). Accumulation of succinate can be transported from the mitochondria to cytosol where in excess it impairs the activity of Prolyl hydroxylases (PHDs), which in turn leads to HIF- $1 \alpha$ stabilization and pro-inflammatory IL-1 $\beta$ production $(74,104)$. Accumulation of succinate from the tricarboxylic acid cycle contributes to activation of the NLRP3 (NOD-like receptor family, pyrin domain containing) inflammasome (105) to activate IL-1 $\beta$. Succinate also contributes to mitochondrial ROS (mROS) formation. mROS exacerbates issue injury after ischemia-reperfusion (106). Accumulations in succinate may be reoxidized by succinate dehydrogenase upon reperfusion, driving extensive ROS generation by reverse electron transport at mitochondrial complex I (104). Decreasing ischemic succinate accumulation is sufficient to ameliorate ischemia reperfusion injury in murine models of heart attacks (107).

Accumulating evidence highlights the importance of mitochondrial dysfunction in inflammation and cardiovascular disease. In macrophages, mitochondrial dysfunction prevents repolarization of inflammatory macrophages (108), and the NLRP3 inflammasome senses mitochondrial dysfunction (105). Recent findings provide evidence for mitochondrial DNA damage and decreased activity of mitochondrial electron transport complexes (109) and mitochondrial respiration (110) in coronary artery disease; restoring mitochondrial DNA copy number in these settings may be ameliorative (111). Mitochondrial dysfunction is characterized by uncoupling of the electron transport chain, reduced production of adenosine triphosphate, and elevated production of ROS. Excessive mROS may do damage to mitochondrial DNA. Mitochondrial DNA damage and dysfunction is also associated with oxidative stress post MI. For example, compared to control, the mtDNA-encoded gene transcripts of CI and CIII of the electron transport chain are decreased, along with the enzyme activity of complexes I, III, and IV after MI (112). Ultimately, dysfunctional mitochondria may be cleared or metabolized through mitophagy.

\section{Mitochondria in Anti-inflammatory Processes}

In comparison to initial links between glycolytic metabolism and pro-inflammatory macrophage activation, our understanding of metabolic integration with anti-inflammatory macrophage polarization has trailed behind, yet has made significant recent strides forward. During aerobic respiration, glycolytic pyruvate is shuttled to the mitochondria for entry into the enzymecatalyzed reactions of the tricarboxylic acid cycle (113). In studies that employed 2-deoxy-D-glucose (2DG) to competitively inhibit the production of glucose-6-phosphate from glucose, glycolysis was implicated in generation of pyruvate for entry into the TCA cycle, as well as regulation of interleukin-4 dependent oxidative phosphorylation (114). In addition, glycolysis may contribute to alternative macrophage activation via an M-CSFinduced mTORC2-IR4 axis, acting in parallel with IL-4R $\alpha /$ Stat6 signaling (114). However, a recent study concluded that glycolysis is not required for alternative activation of macrophages. The differences between the studies may be explained by off-target effects of 2-DG on oxidative phosphorylation and the TCA cycle (115). Prior studies associated cell-intrinsic lipolysis and fatty acid oxidation to IL-4 induced macrophage polarization by etomoxir (ETO), an inhibitor of carnitine palmitoyl transferase (CPT1) (116). Subsequent studies in Cpt1adeficient macrophages did not reveal contributions of LCfatty acid oxidation during alternative macrophage polarization. Rather, etomoxir was found to have the potential to reduce the pool of Coenzyme A (CoA) during IL-4-triggerd macrophage polarization (117). Furthermore, Cpt-2-deficient macrophages also did not show impaired macrophage polarization, raising further questions on the role of long chain fatty acid oxidation (LC-FAO) and macrophage polarization (118). Nevertheless, inhibition of mitochondrial oxidative phosphorylation has been shown to prevent repolarization from classically activated to alternatively activated macrophages. For example, inhibiting nitric oxide production in classically activated macrophages dampens declines in mitochondrial function and facilitates repolarization to the alternative state (108). IL4 may have potential post MI in promoting reparative phase cardiac macrophages (119). 


\section{Mitochondrial Metabolism and Epigenetic Modulation}

Epigenetics play a key role in the establishment of the so called M1 and M2 program. $\alpha$-KG produced by the Krebs cycle, or generated from glutaminolysis, is an important co-factor for numerous enzymes involved in epigenetic modification of DNA and histones (120). Among these enzymes, Jmjd3, an essential H3K27 demethylase, has been reported to promote M2 activation whereas its activity attenuates inflammation in classically activated macrophages. In M2 macrophages, $\alpha-K G$ accumulates whereas its abundance is decreased in M1 macrophages due to its broken Krebs cycle, as well as a higher $\alpha$-KG dehydrogenase activity to the benefit of succinate accumulation (102). Interestingly, $\alpha-K G /$ succinate ratio can modulate Jmjd3 activity (121). Thus, manipulation of this ratio may allow the control of macrophage polarization state. Another example of the epigenetic control over macrophage inflammatory status is given by TET2, a deoxyribonucleic acid (DNA) methyltransferase that is highly expressed in macrophages. TET2 restricts inflammatory gene activation through DNA methylation at 5methylcytosine sites, whereas its deletion increases inflammation at basal levels and after LPS stimulation (122). Interestingly, in experimental mice harboring Tet2 deletion, myeloid Tet2 deficiency accelerated heart failure through the IL-1 $\beta / N L R P 3$ inflammasome (123). Clonal hematopoiesis associated with Tet2deficiency has been shown to accelerate atherosclerosis in experimental mice $(124,125)$, whereas whole-exome sequencing of carriers of clonal hematopoiesis of indeterminate potential (CHIP) patients indicated that mutations in TET2 are associated with heightened coronary heart disease risk (125).

\section{Clearance and Catabolism of Dying Cardiomyocytes and Apoptotic Cells by Efferocytosis (126) Is Necessary for Cardiac Repair $(127,128)$}

Efferocytosis is distinct mechanistically and metabolically to the substrates acquired during microbial phagocytosis. The engulfment of dying cells has the capacity to double the phagocyte cellular content and provide new nutrient substrates for signaling reactions. Early studies connected the cellular metabolism of efferocytosis to generation of high energy phosphates which are necessary for actin-mediated engulfment of apoptotic bodies (45). Later studies elucidated roles for mitochondrial uncoupling proteins in regulating continued dying cell engulfment (129). Also, mitochondrial fission machinery (130) is necessary for multiple rounds of efferocytosis, which is likely critical to tissue injury that is characterized by heightened cell turnover. These later scenarios suggest conserved relationships and feedback mechanisms between mitochondrial metabolic sensing and uptake of dying cells. In the case of myocardial infarction and after ischemic reperfusion, dying cardiomyocytes are engulfed by recruited and resident cardiac macrophages $(128,131)$; this correlates directly with both heightened macrophage oxygen consumption and anti-inflammatory Il10 cytokine expression. IL-10 is a hallmark cytokine produced in disparate settings of tissue injury. Within the re-perfused myocardium, IL-10 is produced and linked to the regulation of extracellular matrix biosynthesis (132) and cardiac repair (133). IL10 is linked to inflammation resolution and may inhibit toll like receptor-associated glucose uptake through mTOR and induce macrophage polarization toward oxidative phosphorylation (134). Consistent with these relationships, macrophages fed apoptotic cells exhibit a transcriptional and metabolic signature polarized for fatty acid oxidation, and mitochondrial organelles can be found in close proximity to phagosomes. So how might mitochondrial metabolism be linked to anti-inflammatory cytokine production? One answer may be NAD. The citric acid cycle generates NADH reducing equivalents which are fed into the electron transport chain for oxidative phosphorylation (113). Efferocytosis increases NAD+, and NAD is sufficient to for efferocytic-induced IL10 through the activation of Sirtuin-mediated signaling (135). In comparison, glucose availability is linked to both lower cytosolic NADH:NAD+ ratios and reduced NF-kB activation, and macrophage proinflammatory gene expression. This can be rescued by forced elevation of $\mathrm{NADH}$, or reduced expression of the NADHsensitive transcriptional co-repressor CtBP (136). Efferocytosis also triggers phagocyte polarization and metabolic parallels and distinctions may be made between efferocytic-induced polarization vs. cytokine-induced. For example, alternative polarization of macrophages by interleukin-4 (IL-4) has also been linked to the mobilization of intra- and extra-cellular free fatty acids (FFAs). However, unlike after IL-4, glycolytic requirements may be unnecessary for efferocytic-induced IL10.

An understanding of these basic mechanisms of efferocytic metabolism is important in the context that cardiovascular disease is associated with impaired phagocytosis $(137,138)$ and metabolic imbalance. For example, obesity is linked to defective efferocytosis in association with elevated levels of saturated fatty acids. This may be corrected by the action of omega-3 fatty acids (139). Impairments of cholesterol efflux from macrophages under conditions of excess lipid, as occurs during cardiovascular disease, may lead to macrophage death (140). Interestingly, lysosomal cholesterol hydrolysis couples efferocytosis to anti-inflammatory oxysterol production (141). Thus, cellular imbalances of metabolites during disease could in principle dysregulate the integrated metabolic response of macrophages to promote tissue repair.

\section{Amino Acids}

Amino acids are utilized for numerous anabolic reactions in macrophages and are sensed by mammalian target of the rapamycin (mTOR) (142). mTOR-inhibitors such as rapamycin block immune cell activation and can inhibit allograft rejection. mTOR is particularly sensitive to branched-chain amino acids/BCAAs (143). The BCAA isoleucine is required for cell proliferation in a mTORC1-dependent pathway. For example, experimental mice fed a BCAA-reduced diet exhibited decreased numbers of Foxp $3^{+}$T-regulatory cells (144). BCAA catabolism is initiated by branched-chain aminotransferase (BCAT) enzymes. BCATs transfer $\alpha$-amino groups from BCAAs to $\alpha \mathrm{KG}$ and BCAT1 deficiency can lead to alpha-KG accumulation (145). Furthermore, selective inhibition of BCAT1 
activity by the compound ERG240 leads to decreased oxygen consumption and glycolysis through the down regulation of IRG1 expression, which leads to decrease itaconate production in human macrophages. ERG240 has also been shown to reduce macrophage migration and inflammatory responses in immunemediated inflammation (146). Further studies are warranted to test this pathway in disparate inflammatory settings of inflammation, including heart.

One of the earliest links between amino acids and phagocytes was the discovery that arginine is important to macrophage function. Classically activated macrophages metabolize L-arginine through inducible nitric oxide synthase (147) whereas alternatively activated macrophages metabolize Larginine trough arginase-1 (Arg1) (148). Macrophages that are stimulated with TLR ligands express nitric oxide synthase, which metabolizes arginine to nitric oxide and citrulline (149). Extracellular arginine supports the initial burst of NO, which is also required for control of infection (150). In comparison, alternatively activated macrophages express Arg1 that hydrolyzes arginine to ornithine and urea. In this setting, Arg1-deficiency in macrophages leads to increased pro-inflammatory macrophage polarization (151). In heart, L-arginine is associated with a higher risk of ischemic heart disease, and L-arginine administration post-infarction may be associated with a higher post-infarction mortality (152). Interestingly, oral administration of arginine improved wound healing and increased insulin-like growth factor-1 (IGF1) in post-surgery patients (153). Also, inhibition of Arg1 activity did not alter alternatively activated macrophage numbers but increased local inflammation and defects in matrix deposition (154).

\section{Glutamine}

may also be important in proliferating immune cells as an alternative input for the TCA cycle, or as a source of citrate for fatty acid synthesis. For example, glutamine has recently been implicated in T-cell metabolism (155). In phagocytes, glutamine metabolism provides support for macrophage activation. Multiple polarization states of macrophages rely on glutamine to mount desirable immune functions. For example, classically activated macrophages exhibit increased glucose and glutamine consumption and suppress oxidative metabolism (156). In IL-4 activated macrophages, the TCA cycle is intact and glutamine is metabolized into UDP-GlcNAc, which is important for glycosylation of lectin or mannose receptors for pathogen recognition. Glutamine deprivation reduces this macrophage polarization (101). Later studies reported that glutamine supports alternative macrophage activation through suppressing NFKB-dependent classical macrophage activation. $\alpha \mathrm{KG}$ generated through glutaminolysis is required for PHD-dependent proline hydroxylation of IKK $\beta$, thus suppressing NF- $\mathrm{KB}$ downstream of LPS. In vivo, glutamine metabolism supports induction of endotoxin tolerance in an $\alpha \mathrm{KG}$ dependent manner (121). Glutamine metabolism has also been shown to be increased in trained monocytes. For example, glutaminolysis led to replenishment of the TCA cycle and accumulation of fumarate. Fumarate induced monocyte epigenetic reprogramming by inhibiting KDM5 histone demethylases. Inhibiting glutaminolysis and cholesterol metabolism inhibited blocked trained immunity in monocytes (157). Moreover, glutamine deficiency reduced lipid-induced lysosome dysfunction, mTORC1 activity, and thereby increased autophagy and reduced cell death in macrophages (158). During ischemic heart disease, glutamine enhances recovery from acute ischemia in isolated rate hearts. Furthermore, post-ischemic reperfusion of isolated rat hearts with glutamine resulted in a full recovery of cardiac output (159).

\section{Summary and Future Research}

The field of immunometabolism arose to integrate cellular nutrient metabolism with innate and adaptive immune cell function. Largely absent are past preconceived notions that cellular nutrient processing is solely for energetic currency. Nutritional status has long been associated with optimal wound healing, yet early molecular interest grew in part from pioneering recognition of the association between excess metabolism and cell stress (160). During tissue injury, the integration of information between nutrient availability and anabolic needs leads cells to adapt their metabolism to ensure their functions.

In the translational and clinical arena, current interest of relationships between metabolism and inflammation is high. Compounds that were initially prioritized for metabolic benefit, also act through immunometabolic nodes. For example, the insulin sensitizer metformin (dimethylbiguanide) has effects beyond glucose control. Metformin stimulates the energy sensor AMP-activated protein kinase (AMPK), which is activated during nutrient deficiency (161). Induction of AMPK elevates the fatty acid transporter CPT1 and drives $\beta$-oxidation. Simultaneously, AMPK may antagonize inflammatory $\mathrm{NF} \kappa \mathrm{B}$ gene expression and has been implicated in anti-inflammatory macrophages through an axis of SIRT1-PGC-1 $\alpha$ mitochondrial biogenesis (162). AMPK also inhibits the glycolytic-inhibitor mTOR (163), and mTOR-inhibitor rapamycin has been shown to attenuate myocardial damage after ischemia reperfusion (164). Separately, inhibitors of the sodium-glucose cotransporter SGLT2 may have promise in cardiovascular outcomes (165), yet their action on macrophages are unclear and caution must be taken given potential side effects of urinary tract infections. In comparison, drugs that directly target inflammatory cytokines, may also regulate cellular metabolism. For instance, IL-1 $\beta$ is notable as introduced above for its sensitivity and responsiveness to metabolic alterations (166). Another case in point is the finding that elevated glucose levels after feeding induces macrophage IL-1 $\beta$ secretion (167). In the case of myocardial infarction (MI), IL-1 $\beta$ is markedly upregulated in infarcted myocardium (168) and in blood (169), paralleling peripheral cell blood counts. Preclinical studies have shown that anti-IL-1 $\beta$ therapy reduced post MI hematopoiesis and leukocytosis, enhanced inflammation resolution in the infarct, and ameliorated postMI heart failure (170). The landmark Canakinumab Antiinflammatory Thrombosis Outcome Study (CANTOS) inhibited interleukin $1 \beta$ (IL-1B) in survivors of myocardial infarction and reduced cardiovascular events $(171,172)$. However, IL$1 \beta$ exerts both detrimental and beneficial effects (173). Thus, further studies are warranted to optimize the full potential of 
IL-1 $\beta$ targeting in heart, as well as potential immunometabolic consequences (174). This is particularly the case in the face of recent negative clinical results after treatment with low dose methotrexate (175).

Because of the complicated integration and flux of numerous metabolic pathways, an informed future perspective will benefit from a coupled global network analysis of metabolomics and inflammatory signaling axes. As an example, integrated topdown transcriptional and metabolic omics approaches were key in revealing that pro-inflammatory macrophages exhibit a disrupted TCA cycle (101). These global and non-biased methods are necessary to completely appreciate the heterogeneity of a diverse phagocyte population. Insight into the metabolic activity of single cells holds the potential to uncover nuanced degrees of immunometabolic control, that we do not currently comprehend. In combination with genetic lineage tracing, fate mapping, and epigenetics signatures, we will also better understand how metabolism may regulate immune cell origins and their differentiation during inflammation (176). Surely, we have only scratched the surface of the spectrum of metabolites that are protagonists of signal transduction in immune cells and heart.

Finally, much of our understanding of immunometabolism has originated from studies in cell culture and experimental rodents. Therefore, it will be important to test the conservation of these findings in human cells and in the clinic. These are important considerations given that mice naturally exhibit a

\section{REFERENCES}

1. Benjamin EJ, Virani SS, Callaway CW, Chamberlain AM, Chang AR, Cheng S, et al. Heart disease and stroke statistics-2018 update: a report from the American Heart Association. Circulation. (2018) 137:e67-e492. doi: 10.1161/CIR.0000000000000558

2. Liang CS, Delehanty JD. Increasing post-myocardial infarction heart failure incidence in elderly patients a call for action. J Am Coll Cardiol. (2009) 53:21-3. doi: 10.1016/j.jacc.2008.09.026

3. Hausenloy DJ, Yellon DM. Myocardial ischemia-reperfusion injury: a neglected therapeutic target. J Clin Invest. (2013) 123:92-100. doi: 10.1172/JCI62874

4. Hansson GK, Stemme S, Geng YJ, Holm J. Can immunocompetent cells and their cytokines play a role in atherogenesis? Nouvelle Rev Francaise d'hematol. (1992) 34(Suppl):S43-46.

5. Libby P, Clinton SK. Cytokines as mediators of vascular pathology. Nouvelle Rev Francaise d'hematol. (1992) 34(Suppl):S47-53.

6. Serhan CN, Savill J. Resolution of inflammation: the beginning programs the end. Nat Immunol. (2005) 6:1191-7. doi: 10.1038/ni1276

7. Yvan-Charvet L, Pagler T, Gautier EL, Avagyan S, Siry RL, Han S, et al. ATP-binding cassette transporters and HDL suppress hematopoietic stem cell proliferation. Science. (2010) 328:1689-93. doi: 10.1126/science.1189731

8. Panizzi P, Swirski FK, Figueiredo JL, Waterman P, Sosnovik DE, Aikawa $\mathrm{E}$, et al. Impaired infarct healing in atherosclerotic mice with Ly-6C(hi) monocytosis. J Am Coll Cardiol. (2010) 55:1629-38. doi: 10.1016/j.jacc.2009.08.089

9. Dutta P, Courties G, Wei Y, Leuschner F, Gorbatov R, Robbins CS, et al. Myocardial infarction accelerates atherosclerosis. Nature. (2012) 487:325-9. doi: $10.1038 /$ nature 11260

10. Swirski FK, Nahrendorf M, Etzrodt M, Wildgruber M, Cortez-Retamozo $\mathrm{V}$, Panizzi $\mathrm{P}$, et al. Identification of splenic reservoir monocytes and their deployment to inflammatory sites. Science. (2009) 325:612-6. doi: $10.1126 /$ science. 1175202 basal metabolic rate per gram of body weight that is greater than that of humans. Advancements and accessibility of induced pluripotent stem cells that may be differentiated into immune cells (177) will facilitate human-mouse comparisons, as well as genetic associations. In experimental animals, multiple studies that have targeted inflammatory pathways have shown promise in enhancing cardiac repair, however, a disconnect exists between translating outcomes in preclinical models to improved patient outcomes (178). This is a challenge to understand experimental, species, and clinical distinctions between independent studies. It is also a challenge to dig deeper into fundamental mechanisms that regulate immunometabolic signaling in cardiovascular disease.

\section{AUTHOR CONTRIBUTIONS}

All authors listed have made a substantial, direct and intellectual contribution to the work, and approved it for publication.

\section{ACKNOWLEDGMENTS}

This work was supported by National Institute of Health grants HL122309, HL139812, and AI112522. Publication of this research was supported by the Sidney and Bess Eisenberg Memorial Fund.

11. Nahrendorf M, Swirski FK. Monocyte and macrophage heterogeneity in the heart. Circ Res. (2013) 112:1624-33. doi: 10.1161/CIRCRESAHA.113.300890

12. Frangogiannis NG, Smith CW, Entman ML. The inflammatory response in myocardial infarction. Cardiovasc Res. (2002) 53:31-47. doi: 10.1016/S0008-6363(01)00434-5

13. Whelan RS, Kaplinskiy V, Kitsis RN. Cell death in the pathogenesis of heart disease: mechanisms and significance. Annu Rev Physiol. (2010) 72:19-44. doi: 10.1146/annurev.physiol.010908.163111

14. Chen P, Zuo H, Xiong H, Kolar MJ, Chu Q, Saghatelian A, et al. Gpr132 sensing of lactate mediates tumor-macrophage interplay to promote breast cancer metastasis. Proc Natl Acad Sci USA. (2017) 114:580-5. doi: $10.1073 /$ pnas. 1614035114

15. Krysko DV, Agostinis P, Krysko O, Garg AD, Bachert C, Lambrecht BN, et al. Emerging role of damage-associated molecular patterns derived from mitochondria in inflammation. Trends Immunol. (2011) 32:157-64. doi: 10.1016/j.it.2011.01.005

16. Deniset JF, Kubes P. Recent advances in understanding neutrophils. F1000Research. (2016) 5:2912. doi: 10.12688/f1000research.9691.1

17. Meissner J, Irfan A, Twerenbold R, Mueller S, Reiter M, Haaf P, et al. Use of neutrophil count in early diagnosis and risk stratification of AMI. Am J Med. (2011) 124:534-42. doi: 10.1016/j.amjmed.2010. 10.023

18. Soo A, Maher B, McCarthy J, Nolke L, Wood A, Watson RW. Pre-operative determination of an individual's neutrophil response: a potential predictor of early cardiac transplant cellular rejection. J Heart Lung Transplant. (2009) 28:1198-205. doi: 10.1016/j.healun.2009. 05.026

19. Dragu R, Khoury S, Zuckerman R, Suleiman M, Mutlak D, Agmon $\mathrm{Y}$, et al. Predictive value of white blood cell subtypes for long-term outcome following myocardial infarction. Atherosclerosis. (2008) 196:40512. doi: 10.1016/j.atherosclerosis.2006.11.022

20. Chia S, Nagurney JT, Brown DF, Raffel OC, Bamberg F, Senatore F, et al. Association of leukocyte and neutrophil counts with infarct size, left 
ventricular function and outcomes after percutaneous coronary intervention for ST-elevation myocardial infarction. Am J Cardiol. (2009) 103:333-7. doi: 10.1016/j.amjcard.2008.09.085

21. Ali M, Pulli B, Courties G, Tricot B, Sebas M, Iwamoto Y, et al. Myeloperoxidase inhibition improves ventricular function and remodeling after experimental myocardial infarction. JACC Basic Trans Sci. (2016) 1:633-43. doi: 10.1016/j.jacbts.2016.09.004

22. Romson JL, Hook BG, Kunkel SL, Abrams GD, Schork MA, Lucchesi BR. Reduction of the extent of ischemic myocardial injury by neutrophil depletion in the dog. Circulation. (1983) 67:1016-23. doi: 10.1161/01.CIR.67.5.1016

23. Nijhuis J, Rensen SS, Slaats Y, van Dielen FM, Buurman WA, Greve JW. Neutrophil activation in morbid obesity, chronic activation of acute inflammation. Obesity. (2009) 17:2014-8. doi: 10.1038/oby.20 09.113

24. Mazor R, Shurtz-Swirski R, Farah R, Kristal B, Shapiro G, Dorlechter F, et al. Primed polymorphonuclear leukocytes constitute a possible link between inflammation and oxidative stress in hyperlipidemic patients. Atherosclerosis. (2008) 197:937-43. doi: 10.1016/j.atherosclerosis.2007. 08.014

25. Wong SL, Demers M, Martinod K, Gallant M, Wang Y, Goldfine AB, et al. Diabetes primes neutrophils to undergo NETosis, which impairs wound healing. Nat Med. (2015) 21:815-9. doi: 10.1038/nm.3887

26. Horckmans M, Ring L, Duchene J, Santovito D, Schloss MJ, Drechsler $\mathrm{M}$, et al. Neutrophils orchestrate post-myocardial infarction healing by polarizing macrophages towards a reparative phenotype. Eur Heart J. (2017) 38:187-97. doi: 10.1093/eurheartj/ehw002

27. Ma Y, Yabluchanskiy A, Iyer RP, Cannon PL, Flynn ER, Jung M, et al. Temporal neutrophil polarization following myocardial infarction. Cardiovasc Res. (2016) 110:51-61. doi: 10.1093/cvr/cvw024

28. Fridlender ZG, Sun J, Kim S, Kapoor V, Cheng G, Ling L, et al. Polarization of tumor-associated neutrophil phenotype by TGF-beta: "N1" versus "N2" TAN. Cancer Cell. (2009) 16:183-94. doi: 10.1016/j.ccr.2009.06.017

29. Early JO, Curtis AM. Immunometabolism: is it under the eye of the clock? Semin Immunol. (2016) 28:478-90. doi: 10.1016/j.smim.2016.10.006

30. Dallmann R, Viola AU, Tarokh L, Cajochen C, Brown SA. The human circadian metabolome. Proc Natl Acad Sci USA. (2012) 109:2625-9. doi: 10.1073/pnas.1114410109

31. Eckel-Mahan KL, Patel VR, Mohney RP, Vignola KS, Baldi P, SassoneCorsi P. Coordination of the transcriptome and metabolome by the circadian clock. Proc Natl Acad Sci USA. (2012) 109:5541-6. doi: 10.1073/pnas.1118726109

32. Hong HK, Maury E, Ramsey KM, Perelis M, Marcheva B, Omura C, et al. Requirement for NF-kappaB in maintenance of molecular and behavioral circadian rhythms in mice. Genes Dev. (2018) 32:1367-79. doi: $10.1101 / \mathrm{gad} .319228 .118$

33. Casanova-Acebes M, Pitaval C, Weiss LA, Nombela-Arrieta C, Chevre RN. Rhythmic modulation of the hematopoietic niche through neutrophil clearance. Cell. (2013) 153:1025-35. doi: 10.1016/j.cell.2013.04.040

34. Schloss MJ, Horckmans M, Nitz K, Duchene J, Drechsler M, Bidzhekov $\mathrm{K}$, et al. The time-of-day of myocardial infarction onset affects healing through oscillations in cardiac neutrophil recruitment. EMBO Mol Med. (2016) 8:937-48. doi: 10.15252/emmm.201506083

35. Kalsbeek A, Yi CX, La Fleur SE, Fliers E. The hypothalamic clock and its control of glucose homeostasis. Trends Endocrinol Metabol. (2010) 21:40210. doi: 10.1016/j.tem.2010.02.005

36. Scheiermann C, Kunisaki Y, Lucas D, Chow A, Jang JE, Zhang D, et al. Adrenergic nerves govern circadian leukocyte recruitment to tissues. Immunity. (2012) 37:290-301. doi: 10.1016/j.immuni.2012.05.021

37. Ella K, Csepanyi-Komi R, Kaldi K. Circadian regulation of human peripheral neutrophils. Brain Behav Immun. (2016) 57:209-21. doi: 10.1016/j.bbi.2016.04.016

38. Peek CB, Affinati AH, Ramsey KM, Kuo HY, Yu W, Sena LA, et al. Circadian clock NAD+ cycle drives mitochondrial oxidative metabolism in mice. Science. (2013) 342:1243417. doi: 10.1126/science.1243417

39. Gaul DS, Weber J, van Tits LJ, Sluka S, Pasterk L, Reiner MF, et al. Loss of Sirt3 accelerates arterial thrombosis by increasing formation of neutrophil extracellular traps and plasma tissue factor activity. Cardiovasc Res. (2018) 114:1178-88. doi: $10.1093 / \mathrm{cvr} / \mathrm{cvy} 036$

40. Riffelmacher T, Clarke A, Richter FC, Stranks A, Pandey S, Danielli $\mathrm{S}$, et al. Autophagy-dependent generation of free fatty acids is critical for normal neutrophil differentiation. Immunity. (2017) 47:466-480.e465. doi: 10.1016/j.immuni.2017.08.005

41. Rozman S, Yousefi S, Oberson K, Kaufmann T, Benarafa C, Simon HU. The generation of neutrophils in the bone marrow is controlled by autophagy. Cell Death Differ. (2015) 22:445-56. doi: 10.1038/cdd.2014.169

42. Tanimura A, Miyoshi K, Horiguchi T, Hagita H, Fujisawa K, Noma T. Mitochondrial activity and unfolded protein response are required for neutrophil differentiation. Cell Physiol Biochem. (2018) 47:1936-50. doi: $10.1159 / 000491464$

43. Grenda DS, Murakami M, Ghatak J, Xia J, Boxer LA, Dale D, et al. Mutations of the ELA2 gene found in patients with severe congenital neutropenia induce the unfolded protein response and cellular apoptosis. Blood. (2007) 110:4179-87. doi: 10.1182/blood-2006-11-057299

44. Kollner I, Sodeik B, Schreek S, Heyn H, von Neuhoff N, Germeshausen $\mathrm{M}$, et al. Mutations in neutrophil elastase causing congenital neutropenia lead to cytoplasmic protein accumulation and induction of the unfolded protein response. Blood. (2006) 108:493-500. doi: 10.1182/blood-2005$11-4689$

45. Oren R, Farnham AE, Saito K, Milofsky E, Karnovsky ML. Metabolic patterns in three types of phagocytizing cells. J Cell Biol. (1963) 17:487-501. doi: $10.1083 /$ jcb.17.3.487

46. Hirsch JG, Fedorko ME. Ultrastructure of human leukocytes after simultaneous fixation with glutaraldehyde and osmium tetroxide and "postfixation" in uranyl acetate. J Cell Biol. (1968) 38:615-27. doi: $10.1083 /$ jcb.38.3.615

47. Maianski NA, Geissler J, Srinivasula SM, Alnemri ES, Roos D, Kuijpers TW. Functional characterization of mitochondria in neutrophils: a role restricted to apoptosis. Cell Death Differ. (2004) 11:143-53. doi: 10.1038/sj.cdd.4401320

48. Fossati G, Moulding DA, Spiller DG, Moots RJ, White MR, Edwards SW. The mitochondrial network of human neutrophils: role in chemotaxis, phagocytosis, respiratory burst activation, and commitment to apoptosis. $J$ Immunol. (2003) 170:1964-72. doi: 10.4049/jimmunol.170.4.1964

49. Borregaard N, Herlin T. Energy metabolism of human neutrophils during phagocytosis. J Clin Invest. (1982) 70:550-7. doi: 10.1172/JCI110647

50. Ge L, Zhou X, Ji WJ, Lu RY, Zhang Y, Zhang YD, et al. Neutrophil extracellular traps in ischemia-reperfusion injury-induced myocardial no-reflow: therapeutic potential of DNase-based reperfusion strategy. Am J Physiol Heart Circ Physiol. (2015) 308:H500-9. doi: 10.1152/ajpheart.00381.2014

51. Helseth R, Solheim S, Arnesen H, Seljeflot I, Opstad TB. The time course of markers of neutrophil extracellular traps in patients undergoing revascularisation for acute myocardial infarction or stable angina pectoris. Mediators Inflamm. (2016) 2016:2182358. doi: 10.1155/2016/2182358

52. Rodriguez-Espinosa O, Rojas-Espinosa O, Moreno-Altamirano MM, Lopez-Villegas EO, Sanchez-Garcia FJ. Metabolic requirements for neutrophil extracellular traps formation. Immunology. (2015) 145:213-24. doi: $10.1111 / \mathrm{imm} .12437$

53. Azevedo EP, Rochael NC, Guimaraes-Costa AB, de Souza-Vieira TS, Ganilho J, Saraiva EM, et al. A metabolic shift toward pentose phosphate pathway is necessary for amyloid fibril- and phorbol 12-myristate 13-acetateinduced neutrophil extracellular trap (NET) formation. J Biol Chem. (2015) 290:22174-83. doi: 10.1074/jbc.M115.640094

54. Hong S, Porter TF, Lu Y, Oh SF, Pillai PS, Serhan CN. Resolvin E1 metabolome in local inactivation during inflammation-resolution. $J$ Immunol. (2008) 180:3512-9. doi: 10.4049/jimmunol.180.5.3512

55. Casanova-Acebes M, Nicolas-Avila JA, Li JL, Garcia-Silva S, Balachander A, Rubio-Ponce A, et al. Neutrophils instruct homeostatic and pathological states in naive tissues. J Exp Med. 2018:1468. (2018). doi: $10.1084 /$ jem. 20181468

56. Soehnlein O, Zernecke A, Eriksson EE, Rothfuchs AG, Pham CT, Herwald $\mathrm{H}$, et al. Neutrophil secretion products pave the way for inflammatory monocytes. Blood. (2008) 112:1461-71. doi: 10.1182/blood-2008-02-139634 
57. Soehnlein O, Xie X, Ulbrich H, Kenne E, Rotzius P, Flodgaard H, et al. Neutrophil-derived heparin-binding protein (HBP/CAP37) deposited on endothelium enhances monocyte arrest under flow conditions. J Immunol. (2005) 174:6399-405. doi: 10.4049/jimmunol.174.10.6399

58. De Y, Chen Q, Schmidt AP, Anderson GM, Wang JM, Wooters J, et al. LL37, the neutrophil granule- and epithelial cell-derived cathelicidin, utilizes formyl peptide receptor-like 1 (FPRL1) as a receptor to chemoattract human peripheral blood neutrophils, monocytes, and T cells. J Exp Med. (2000) 192:1069-74. doi: 10.1084/jem.192.7.1069

59. A-Gonzalez N, Bensinger SJ, Hong C, Beceiro S, Bradley MN, Zelcer N, et al. Apoptotic cells promote their own clearance and immune tolerance through activation of the nuclear receptor LXR. Immunity. (2009) 31:245-58. doi: 10.1016/j.immuni.2009.06.018

60. Majai G, Sarang Z, Csomos K, Zahuczky G, Fesus L. PPARgamma-dependent regulation of human macrophages in phagocytosis of apoptotic cells. Eur J Immunol. (2007) 37:1343-54. doi: 10.1002/eji.200636398

61. Fan W, Evans R. PPARs and ERRs: molecular mediators of mitochondrial metabolism. Curr Opin Cell Biol. (2015) 33:49-54. doi: 10.1016/j.ceb.2014.11.002

62. Hard GC. Some biochemical aspects of the immune macrophage. Br J Exp Pathol. (1970) 51:97-105.

63. Newsholme P, Curi R, Gordon S, Newsholme EA. Metabolism of glucose, glutamine, long-chain fatty acids and ketone bodies by murine macrophages. Biochem J. (1986) 239:121-5. doi: 10.1042/bj2390121

64. Lin N, Simon MC. Hypoxia-inducible factors: key regulators of myeloid cells during inflammation. J Clin Invest. (2016) 126:3661-71. doi: 10.1172/JCI84426

65. Chen C, Pore N, Behrooz A, Ismail-Beigi F, Maity A. Regulation of glut1 mRNA by hypoxia-inducible factor-1. Interaction between $\mathrm{H}$-ras and hypoxia. J Biol Chem. (2001) 276:9519-25. doi: 10.1074/jbc.M010144200

66. Riddle SR, Ahmad A, Ahmad S, Deeb SS, Malkki M, Schneider BK, et al. Hypoxia induces hexokinase II gene expression in human lung cell line A549. Am J Physiol Lung Cell Mol Physiol. (2000) 278:L407-416. doi: 10.1152/ajplung.2000.278.2.L407

67. Minchenko A, Leshchinsky I, Opentanova I, Sang N, Srinivas V, Armstead $\mathrm{V}$, et al. Hypoxia-inducible factor-1-mediated expression of the 6phosphofructo-2-kinase/fructose-2,6-bisphosphatase-3 (PFKFB3) gene. Its possible role in the Warburg effect. J Biol Chem. (2002) 277:6183-7. doi: 10.1074/jbc.M110978200

68. Papandreou I, Cairns RA, Fontana L, Lim AL, Denko NC. HIF-1 mediates adaptation to hypoxia by actively downregulating mitochondrial oxygen consumption. Cell Metab. (2006) 3:187-97. doi: 10.1016/j.cmet.2006.01.012

69. Colegio OR, Chu NQ, Szabo AL, Chu T, Rhebergen AM, Jairam V, et al. Functional polarization of tumour-associated macrophages by tumourderived lactic acid. Nature. (2014) 513:559-63. doi: 10.1038/nature13490

70. Imtiyaz HZ, Williams EP, Hickey MM, Patel SA, Durham AC, Yuan LJ, et al. Hypoxia-inducible factor 2alpha regulates macrophage function in mouse models of acute and tumor inflammation. J Clin Invest. (2010) 120:2699-714. doi: 10.1172/JCI39506

71. Dong F, Khalil M, Kiedrowski M, O’Connor C, Petrovic E, Zhou X, et al. Critical role for leukocyte hypoxia inducible factor-1alpha expression in post-myocardial infarction left ventricular remodeling. Circ Res. (2010) 106:601-10. doi: 10.1161/CIRCRESAHA.109.208967

72. Krawczyk CM, Holowka T, Sun J, Blagih J, Amiel E, DeBerardinis RJ, et al. Toll-like receptor-induced changes in glycolytic metabolism regulate dendritic cell activation. Blood. (2010) 115:4742-9. doi: 10.1182/blood-2009-10-249540

73. Zhang W, Lavine KJ, Epelman S, Evans SA, Weinheimer CJ, Barger $\mathrm{PM}$, et al. Necrotic myocardial cells release damage-associated molecular patterns that provoke fibroblast activation in vitro and trigger myocardial inflammation and fibrosis in vivo. J Am Heart Assoc. (2015) 4:e001993. doi: 10.1161/JAHA.115.001993

74. Tannahill GM, Curtis AM, Adamik J, Palsson-McDermott EM, McGettrick AF, Goel G, et al. Succinate is an inflammatory signal that induces IL-1beta through HIF-1alpha. Nature. (2013) 496:238-42. doi: 10.1038/nature11986

75. Palsson-McDermott EM, Curtis AM, Goel G, Lauterbach MA, Sheedy FJ, Gleeson LE, et al. Pyruvate kinase M2 regulates Hif-1alpha activity and IL-1beta induction and is a critical determinant of the warburg effect in LPS-activated macrophages. Cell Metab. (2015) 21:65-80. doi: 10.1016/j.cmet.2014.12.005

76. Cheng SC, Quintin J, Cramer RA, Shepardson KM, Saeed S, Kumar $\mathrm{V}$, et al. mTOR- and HIF-1alpha-mediated aerobic glycolysis as metabolic basis for trained immunity. Science. (2014) 345:1250684. doi: 10.1126/science.1250684

77. Pajuelo D, Gonzalez-Juarbe N, Tak U, Sun J, Orihuela CJ, Niederweis M. $\mathrm{NAD}(+)$ depletion triggers macrophage necroptosis, a cell death pathway exploited by Mycobacterium tuberculosis. Cell Rep. (2018) 24:429-40. doi: 10.1016/j.celrep.2018.06.042

78. Yamamoto T, Byun J, Zhai P, Ikeda Y, Oka S, Sadoshima J. Nicotinamide mononucleotide, an intermediate of NAD+ synthesis, protects the heart from ischemia and reperfusion. PLoS ONE. (2014) 9:e98972. doi: 10.1371/journal.pone.0098972

79. Ahmad Sarji S. Physiological uptake in FDG PET simulating disease. Biomed Imaging Interv J. (2006) 2:e59. doi: 10.2349/biij.2.4.e59

80. Zhang Z, Machac J, Helft G, Worthley SG, Tang C, Zaman AG, et al. Noninvasive imaging of atherosclerotic plaque macrophage in a rabbit model with F-18 FDG PET: a histopathological correlation. BMC Nucl Med. (2006) 6:3. doi: 10.1186/1471-2385-6-3

81. Anzai A, Choi JL, He S, Fenn AM, Nairz M, Rattik S, et al. The infarcted myocardium solicits GM-CSF for the detrimental oversupply of inflammatory leukocytes. J Exp Med. (2017) 214:3293-310. doi: 10.1084/jem.20170689

82. Singh P, Gonzalez-Ramos S, Mojena M, Rosales-Mendoza CE, Emami H, Swanson J, et al. GM-CSF enhances macrophage glycolytic activity in vitro and improves detection of inflammation in vivo. J Nucl Med. (2016) 57:142835. doi: 10.2967/jnumed.115.167387

83. Lee WW, Marinelli B, van der Laan AM, Sena BF, Gorbatov R, Leuschner F, et al. PET/MRI of inflammation in myocardial infarction. J Am Coll Cardiol. (2012) 59:153-63. doi: 10.1016/j.jacc.2011.08.066

84. Lewis AJM, Miller JJ, Lau AZ, Curtis MK, Rider OJ, Choudhury RP, et al. Noninvasive immunometabolic cardiac inflammation imaging using hyperpolarized magnetic resonance. Circ Res. (2018) 122:1084-93. doi: 10.1161/CIRCRESAHA.117.312535

85. Nunes P, Demaurex N, Dinauer MC. Regulation of the NADPH oxidase and associated ion fluxes during phagocytosis. Traffic. (2013) 14:1118-31. doi: $10.1111 /$ tra. 12115

86. Rybicka JM, Balce DR, Khan MF, Krohn RM, Yates RM. NADPH oxidase activity controls phagosomal proteolysis in macrophages through modulation of the lumenal redox environment of phagosomes. Proc Natl Acad Sci USA. (2010) 107:10496-501. doi: 10.1073/pnas.09148 67107

87. Heckmann BL, Boada-Romero E, Cunha LD, Magne J, Green DR. LC3associated phagocytosis and inflammation. J Mol Biol. (2017) 429:3561-76. doi: 10.1016/j.jmb.2017.08.012

88. Lewis GD, Wei R, Liu E, Yang E, Shi X, Martinovic M, et al. Metabolite profiling of blood from individuals undergoing planned myocardial infarction reveals early markers of myocardial injury. J Clin Invest. (2008) 118:3503-12. doi: 10.1172/JCI35111

89. Bories GFP, Leitinger N. Macrophage metabolism in atherosclerosis. FEBS Lett. (2017) 591:3042-60. doi: 10.1002/1873-3468. 12786

90. Zhang Z, Apse K, Pang J, Stanton RC. High glucose inhibits glucose-6phosphate dehydrogenase via cAMP in aortic endothelial cells. J Biol Chem. (2000) 275:40042-7. doi: 10.1074/jbc.M007505200

91. Nagareddy PR, Murphy AJ, Stirzaker RA, Hu Y, Yu S, Miller RG, et al. Hyperglycemia promotes myelopoiesis and impairs the resolution of atherosclerosis. Cell Metab. (2013) 17:695-708. doi: 10.1016/j.cmet.2013.04.001

92. Dutta P, Sager HB, Stengel KR, Naxerova K, Courties G, Saez $\mathrm{B}$, et al. Myocardial infarction activates CCR2 $(+)$ hematopoietic stem and progenitor cells. Cell Stem Cell. (2015) 16:477-87. doi: 10.1016/j.stem.2015.04.008

93. Daffu G, Shen X, Senatus L, Thiagarajan D, Abedini A, Hurtado Del Pozo C, et al. RAGE suppresses ABCG1-mediated macrophage cholesterol efflux in diabetes. Diabetes. (2015) 64:4046-60. doi: 10.2337/db 15-0575 
94. Chandel NS. Evolution of mitochondria as signaling organelles. Cell Metab. (2015) 22:204-6. doi: 10.1016/j.cmet.2015.05.013

95. Liu X, Kim CN, Yang J, Jemmerson R, Wang X. Induction of apoptotic program in cell-free extracts: requirement for dATP and cytochrome c. Cell. (1996) 86:147-57. doi: 10.1016/S0092-8674(00)80085-9

96. Chandel NS, Maltepe E, Goldwasser E, Mathieu CE, Simon MC, Schumacker PT. Mitochondrial reactive oxygen species trigger hypoxiainduced transcription. Proc Natl Acad Sci USA. (1998) 95:11715-20. doi: $10.1073 /$ pnas.95.20.11715

97. Murley A, Nunnari J. The emerging network of mitochondria-organelle contacts. Mol Cell. (2016) 61:648-53. doi: 10.1016/j.molcel.2016. 01.031

98. West AP, Brodsky IE, Rahner C, Woo DK, Erdjument-Bromage H, Tempst $\mathrm{P}$, et al. TLR signalling augments macrophage bactericidal activity through mitochondrial ROS. Nature. (2011) 472:476-80. doi: 10.1038/nature 09973

99. Schagger H, Pfeiffer K. Supercomplexes in the respiratory chains of yeast and mammalian mitochondria. EMBO J. (2000) 19:1777-83. doi: $10.1093 / \mathrm{emboj} / 19.8 .1777$

100. Garaude J, Acin-Perez R, Martinez-Cano S, Enamorado M, Ugolini M, Nistal-Villan E, et al. Mitochondrial respiratory-chain adaptations in macrophages contribute to antibacterial host defense. Nat Immunol. (2016) 17:1037-45. doi: 10.1038/ni.3509

101. Jha AK, Huang SC, Sergushichev A, Lampropoulou V, Ivanova Y, Loginicheva E, et al. Network integration of parallel metabolic and transcriptional data reveals metabolic modules that regulate macrophage polarization. Immunity. (2015) 42:419-30. doi: 10.1016/j.immuni.2015.02.005

102. Lampropoulou V, Sergushichev A, Bambouskova M, Nair S, Vincent EE, Loginicheva E, et al. Itaconate links inhibition of succinate dehydrogenase with macrophage metabolic remodeling and regulation of inflammation. Cell Metab. (2016) 24:158-66. doi: 10.1016/j.cmet.2016.06.004

103. O'Neill LAJ, Artyomov MN. Itaconate: the poster child of metabolic reprogramming in macrophage function. Nat Rev Immunol. (2019). doi: 10.1038/s41577-019-0128-5

104. Mills EL, Kelly B, Logan A, Costa ASH, Varma M, Bryant CE, et al. Succinate dehydrogenase supports metabolic repurposing of mitochondria to drive inflammatory macrophages. Cell. (2016) 167:457-470.e413. doi: 10.1016/j.cell.2016.08.064

105. Zhou R, Yazdi AS, Menu P, Tschopp J. A role for mitochondria in NLRP3 inflammasome activation. Nature. (2011) 469:221-5. doi: 10.1038 /nature09663

106. Kalogeris T, Bao Y, Korthuis RJ. Mitochondrial reactive oxygen species: a double edged sword in ischemia/reperfusion vs preconditioning. Redox Biol. (2014) 2:702-14. doi: 10.1016/j.redox.2014.05.006

107. Chouchani ET, Pell VR, Gaude E, Aksentijevic D, Sundier SY, Robb EL, et al. Ischaemic accumulation of succinate controls reperfusion injury through mitochondrial ROS. Nature. (2014) 515:431-5. doi: 10.1038/nature13909

108. Van den Bossche J, Baardman J, Otto NA, van der Velden S, Neele $\mathrm{AE}$, van den Berg SM, et al. Mitochondrial dysfunction prevents repolarization of inflammatory macrophages. Cell Rep. (2016) 17:684-96. doi: 10.1016/j.celrep.2016.09.008

109. Yu E, Calvert PA, Mercer JR, Harrison J, Baker L, Figg NL, et al. Mitochondrial DNA damage can promote atherosclerosis independently of reactive oxygen species through effects on smooth muscle cells and monocytes and correlates with higher-risk plaques in humans. Circulation. (2013) 128:702-12. doi: 10.1161/CIRCULATIONAHA.113.002271

110. Yu EPK, Reinhold J, Yu H, Starks L, Uryga AK, Foote K, et al. Mitochondrial respiration is reduced in atherosclerosis, promoting necrotic core formation and reducing relative fibrous cap thickness. Arterioscler Thromb Vasc Biol. (2017) 37:2322-32. doi: 10.1161/ATVBAHA.117.310042

111. Foote K, Reinhold J, Yu EPK, Figg NL, Finigan A, Murphy MP, et al. Restoring mitochondrial DNA copy number preserves mitochondrial function and delays vascular aging in mice. Aging Cell. (2018) 2018:e12773. doi: 10.1111 /acel.12773

112. Ide T, Tsutsui H, Hayashidani S, Kang D, Suematsu N, Nakamura K, et al. Mitochondrial DNA damage and dysfunction associated with oxidative stress in failing hearts after myocardial infarction. Circ Res. (2001) 88:529-35. doi: 10.1161/01.RES.88.5.529

113. Zheng J. Energy metabolism of cancer: Glycolysis versus oxidative phosphorylation (Review). Oncol Lett. (2012) 4:1151-7. doi: 10.3892/ol.2012.928

114. Huang SC, Smith AM, Everts B, Colonna M, Pearce EL, Schilling JD, et al. Metabolic reprogramming mediated by the mTORC2-IRF4 signaling axis is essential for macrophage alternative activation. Immunity. (2016) 45:817-30. doi: 10.1016/j.immuni.2016.09.016

115. Wang F, Zhang S, Vuckovic I, Jeon R, Lerman A, Folmes CD, et al. Glycolytic stimulation is not a requirement for M2 macrophage differentiation. Cell Metab. (2018) 28:463-75 e464. doi: 10.1016/j.cmet.2018.08.012

116. Huang SC, Everts B, Ivanova Y, O'Sullivan D, Nascimento M, Smith AM, et al. Cell-intrinsic lysosomal lipolysis is essential for alternative activation of macrophages. Nat Immunol. (2014) 15:846-55. doi: 10.1038/ni.2956

117. Divakaruni AS, Hsieh WY, Minarrieta L, Duong TN, Kim KKO, Desousa BR, et al. Etomoxir inhibits macrophage polarization by disrupting CoA homeostasis. Cell Metab. (2018) 28:490-503 e497. doi: 10.1016/j.cmet.2018.06.001

118. Nomura M, Liu J, Rovira II, Gonzalez-Hurtado E, Lee J, Wolfgang MJ, et al. Fatty acid oxidation in macrophage polarization. Nat Immunol. (2016) 17:216-7. doi: 10.1038/ni.3366

119. Bosurgi L, Cao YG, Cabeza-Cabrerizo M, Tucci A, Hughes LD, Kong Y, et al. Macrophage function in tissue repair and remodeling requires IL-4 or IL13 with apoptotic cells. Science. (2017) 356:1072-6. doi: 10.1126/science.aa i8132

120. Stienstra R, Netea-Maier RT, Riksen NP, Joosten LAB, Netea MG Specific and complex reprogramming of cellular metabolism in myeloid cells during innate immune responses. Cell Metab. (2017) 26:142-56. doi: 10.1016/j.cmet.2017.06.001

121. Liu PS, Wang H, Li X, Chao T, Teav T, Christen S, et al. alpha-ketoglutarate orchestrates macrophage activation through metabolic and epigenetic reprogramming. Nat Immunol. (2017) 18:985-94. doi: 10.1038/ni.3796

122. Cull AH, Snetsinger B, Buckstein R, Wells RA, Rauh MJ. Tet2 restrains inflammatory gene expression in macrophages. Exp Hematol. (2017) 55:5670 e13. doi: 10.1016/j.exphem.2017.08.001

123. Sano S, Oshima K, Wang Y, MacLauchlan S, Katanasaka Y, Sano M, et al. Tet2-mediated clonal hematopoiesis accelerates heart failure through a mechanism involving the IL-1beta/NLRP3 inflammasome. J Am Coll Cardiol. (2018) 71:875-86. doi: 10.1016/j.jacc.2017.12.037

124. Fuster JJ, MacLauchlan S, Zuriaga MA, Polackal MN, Ostriker AC, Chakraborty R, et al. Clonal hematopoiesis associated with TET2 deficiency accelerates atherosclerosis development in mice. Science. (2017) 355:842-7. doi: $10.1126 /$ science.aag 1381

125. Jaiswal S, Natarajan P, Silver AJ, Gibson CJ, Bick AG, Shvartz E, et al. Clonal hematopoiesis and risk of atherosclerotic cardiovascular disease. $N$ Engl J Med. (2017) 377:111-21. doi: 10.1056/NEJMoa1701719

126. Henson PM. Cell removal: efferocytosis. Annu Rev Cell Dev Biol. (2017) 33:127-44. doi: 10.1146/annurev-cellbio-111315-125315

127. Howangyin KY, Zlatanova I, Pinto C, Ngkelo A, Cochain C, Rouanet $\mathrm{M}$, et al. Myeloid-epithelial-reproductive receptor tyrosine kinase and milk fat globule epidermal growth factor 8 coordinately improve remodeling after myocardial infarction via local delivery of vascular endothelial growth factor. Circulation. (2016) 133:826-39. doi: 10.1161/CIRCULATIONAHA.115.020857

128. Wan E, Yeap XY, Dehn S, Terry R, Novak M, Zhang S, et al. Enhanced efferocytosis of apoptotic cardiomyocytes through myeloid-epithelialreproductive tyrosine kinase links acute inflammation resolution to cardiac repair after infarction. Circ Res. (2013) 113:1004-12. doi: 10.1161/CIRCRESAHA.113.301198

129. Park D, Han CZ, Elliott MR, Kinchen JM, Trampont PC, Das S, et al. Continued clearance of apoptotic cells critically depends on the phagocyte Ucp2 protein. Nature. (2011) 477:220-4. doi: 10.1038/nature10340

130. Wang Y, Subramanian M, Yurdagul AJr, Barbosa-Lorenzi VC, Cai B, de Juan-Sanz J, et al. Mitochondrial Fission Promotes the Continued Clearance of Apoptotic Cells by Macrophages. Cell. (2017) 171:331-45.e22. doi: 10.1016/j.cell.2017.08.041 
131. DeBerge M, Yeap XY, Dehn S, Zhang S, Grigoryeva L, Misener S, et al. MerTK cleavage on resident cardiac macrophages compromises repair after myocardial ischemia reperfusion injury. Circ Res. (2017) 121:930-40. doi: 10.1161/CIRCRESAHA.117.311327

132. Frangogiannis NG. The extracellular matrix in myocardial injury, repair, and remodeling. J Clin Invest. (2017) 127:1600-12. doi: 10.1172/JCI 87491

133. Krishnamurthy P, Rajasingh J, Lambers E, Qin G, Losordo DW, Kishore R. IL-10 inhibits inflammation and attenuates left ventricular remodeling after myocardial infarction via activation of STAT3 and suppression of HuR. Circ Res. (2009) 104:18. doi: 10.1161/CIRCRESAHA.108.188243

134. Ip WKE, Hoshi N, Shouval DS, Snapper S, Medzhitov R. Anti-inflammatory effect of IL-10 mediated by metabolic reprogramming of macrophages. Science. (2017) 356:513-9. doi: 10.1126/science.aal3535

135. Zhang S, Weinberg S, DeBerge M, Gainullina A, Schipma M, Kinchen JM, et al. Efferocytosis fuels requirements of fatty acid oxidation and the electron transport chain to polarize macrophages for tissue repair. Cell Metab. (2019) 29:443-456.e445. doi: 10.1016/j.cmet.2018.12.004

136. Shen Y, Kapfhamer D, Minnella AM, Kim JE, Won SJ, Chen Y, et al. Bioenergetic state regulates innate inflammatory responses through the transcriptional co-repressor CtBP. Nat Commun. (2017) 8:624. doi: 10.1038/s41467-017-00707-0

137. Schrijvers DM, De Meyer GR, Kockx MM, Herman AG, Martinet W. Phagocytosis of apoptotic cells by macrophages is impaired in atherosclerosis. Arterioscler Thromb Vasc Biol. (2005) 25:1256-61. doi: 10.1161/01.ATV.0000166517.18801.a7

138. Tabas I. Macrophage death and defective inflammation resolution in atherosclerosis. Nat Rev Immunol. (2010) 10:36-46. doi: 10.1038/nri2675

139. Li S, Sun Y, Liang CP, Thorp EB, Han S, Jehle AW, et al. Defective phagocytosis of apoptotic cells by macrophages in atherosclerotic lesions of ob/ob mice and reversal by a fish oil diet. Circ Res. (2009) 105:1072-82. doi: 10.1161/CIRCRESAHA.109.199570

140. Yvan-Charvet L, Pagler TA, Seimon TA, Thorp E, Welch CL, Witztum $\mathrm{JL}$, et al. ABCA1 and ABCG1 protect against oxidative stress-induced macrophage apoptosis during efferocytosis. Circ Res. (2010) 106:1861-9. doi: 10.1161/CIRCRESAHA.110.217281

141. Viaud M, Ivanov S, Vujic N, Duta-Mare M, Aira LE, Barouillet $\mathrm{T}$, et al. Lysosomal cholesterol hydrolysis couples efferocytosis to anti-inflammatory oxysterol production. Circ Res. (2018) 122:1369-84. doi: 10.1161/CIRCRESAHA.117.312333

142. Wolfson RL, Sabatini DM. The dawn of the age of amino acid sensors for the mTORC1 pathway. Cell Metab. (2017) 26:301-9. doi: 10.1016/j.cmet.2017.07.001

143. Zhenyukh O, Civantos E, Ruiz-Ortega M, Sanchez MS, Vazquez C, Peiro C, et al. High concentration of branched-chain amino acids promotes oxidative stress, inflammation and migration of human peripheral blood mononuclear cells via mTORC1 activation. Free Radic Biol Med. (2017) 104:165-77. doi: 10.1016/j.freeradbiomed.2017. 01.009

144. Ikeda K, Kinoshita M, Kayama H, Nagamori S, Kongpracha P, Umemoto $\mathrm{E}$, et al. Slc3a2 mediates branched-chain amino-acid-dependent maintenance of regulatory $\mathrm{T}$ Cells. Cell Rep. (2017) 21:1824-38. doi: 10.1016/j.celrep.2017.10.082

145. Raffel S, Falcone M, Kneisel N, Hansson J, Wang W, Lutz C, et al. BCAT1 restricts alphaKG levels in AML stem cells leading to IDHmutlike DNA hypermethylation. Nature. (2017) 551:384-8. doi: 10.1038/nature 24294

146. Papathanassiu AE, Ko JH, Imprialou $\mathrm{M}$, Bagnati $\mathrm{M}$, Srivastava $\mathrm{PK}, \mathrm{Vu} \mathrm{HA}$, et al. BCAT1 controls metabolic reprogramming in activated human macrophages and is associated with inflammatory diseases. Nat Commun. (2017) 8:16040. doi: 10.1038/ncomms 16040

147. Kwon NS, Nathan CF, Gilker C, Griffith OW, Matthews DE, Stuehr DJ. Lcitrulline production from L-arginine by macrophage nitric oxide synthase. The ureido oxygen derives from dioxygen. J Biol Chem. (1990) 265:13442-5.

148. Granger DL, Hibbs JB Jr, Perfect JR, Durack DT. Specific amino acid (L-arginine) requirement for the microbiostatic activity of murine macrophages. J Clin Invest. (1988) 81:1129-36. doi: 10.1172/JCI 113427

149. Hibbs JB Jr, Taintor RR, Vavrin Z. Macrophage cytotoxicity: role for Larginine deiminase and imino nitrogen oxidation to nitrite. Science. (1987) 235:473-6. doi: 10.1126/science. 2432665

150. Qualls JE, Subramanian C, Rafi W, Smith AM, Balouzian L, DeFreitas AA, et al. Sustained generation of nitric oxide and control of mycobacterial infection requires argininosuccinate synthase 1. Cell Host Microbe. (2012) 12:313-23. doi: 10.1016/j.chom.2012.07.012

151. El Kasmi KC, Qualls JE, Pesce JT, Smith AM, Thompson RW, HenaoTamayo $\mathrm{M}$, et al. Toll-like receptor-induced arginase 1 in macrophages thwarts effective immunity against intracellular pathogens. Nat Immunol. (2008) 9:1399-406. doi: 10.1038/ni.1671

152. Schulman SP, Becker LC, Kass DA, Champion HC, Terrin ML, Forman S, et al. L-arginine therapy in acute myocardial infarction: the Vascular Interaction With Age in Myocardial Infarction (VINTAGE MI) randomized clinical trial. JAMA. (2006) 295:58-64. doi: 10.1001/jama.295. 1.58

153. Kirk SJ, Hurson M, Regan MC, Holt DR, Wasserkrug HL, Barbul A. Arginine stimulates wound healing and immune function in elderly human beings. Surgery. (1993) 114:155-9; discussion 160.

154. Campbell L, Saville CR, Murray PJ, Cruickshank SM, Hardman MJ. Local arginase 1 activity is required for cutaneous wound healing. I Invest Dermatol. (2013) 133:2461-70. doi: 10.1038/jid.2013.164

155. Gerriets VA, Kishton RJ, Nichols AG, Macintyre AN, Inoue M, Ilkayeva O, et al. Metabolic programming and PDHK1 control CD4+ T cell subsets and inflammation. J Clin Invest. (2015) 125:194-207. doi: 10.1172/JCI7 6012

156. O’Neill LA, Kishton RJ, Rathmell J. A guide to immunometabolism for immunologists. Nat Rev Immunol. (2016) 16:553-65. doi: $10.1038 /$ nri.2016.70

157. Arts RJ, Novakovic B, Ter Horst R, Carvalho A, Bekkering S, Lachmandas E, et al. Glutaminolysis and fumarate accumulation integrate immunometabolic and epigenetic programs in trained immunity. Cell Metab. (2016) 24:807-19. doi: 10.1016/j.cmet.2016.10.008

158. He L, Weber KJ, Schilling JD. Glutamine modulates macrophage lipotoxicity. Nutrients. (2016) 8:215. doi: 10.3390/nu804 0215

159. Khogali SE, Pringle SD, Weryk BV, Rennie MJ. Is glutamine beneficial in ischemic heart disease? Nutrition. (2002) 18:123-6. doi: 10.1016/S0899-9007(01)00768-7

160. Hotamisligil GS. Endoplasmic reticulum stress and the inflammatory basis of metabolic disease. Cell. (2010) 140:900-17. doi: 10.1016/j.cell.2010. 02.034

161. Hardie DG, Ross FA, Hawley SA. AMPK: a nutrient and energy sensor that maintains energy homeostasis. Nat Rev Mol Cell Biol. (2012) 13:251-62. doi: $10.1038 / \mathrm{nrm} 3311$

162. Yeung F, Hoberg JE, Ramsey CS, Keller MD, Jones DR, Frye RA, et al. Modulation of NF-kappaB-dependent transcription and cell survival by the SIRT1 deacetylase. Embo J. (2004) 23:2369-80. doi: $10.1038 /$ sj.emboj.7600244

163. Kimura N, Tokunaga C, Dalal S, Richardson C, Yoshino K, Hara $\mathrm{K}$, et al. A possible linkage between AMP-activated protein kinase (AMPK) and mammalian target of rapamycin (mTOR) signalling pathway. Genes Cells. (2003) 8:65-79. doi: 10.1046/j.1365-2443.2003.0 0615.x

164. Filippone SM, Samidurai A, Roh SK, Cain CK, He J, Salloum FN, et al. Reperfusion therapy with rapamycin attenuates myocardial infarction through activation of AKT and ERK. Oxid Med Cell Longev. (2017) 2017:4619720. doi: 10.1155/2017/4619720

165. Zinman B, Wanner C, Lachin JM, Fitchett D, Bluhmki E, Hantel S, et al. Empagliflozin, cardiovascular outcomes, and mortality in type 2 diabetes. N Engl J Med. (2015) 373:2117-28. doi: 10.1056/NEJMoa15 04720

166. Palsson-McDermott EM, Curtis AM, Goel G, Lauterbach MAR, Sheedy FJ, Gleeson LE, et al. Pyruvate kinase M2 regulates Hif-1alpha activity and IL-1beta induction and is a critical determinant of the 
warburg effect in LPS-activated macrophages. Cell Metab. (2015) 21:347. doi: 10.1016/j.cmet.2015.01.017

167. Dror E, Dalmas E, Meier DT, Wueest S, Thevenet J, Thienel C, et al. Postprandial macrophage-derived IL-1beta stimulates insulin, and both synergistically promote glucose disposal and inflammation. Nat Immunol. (2017) 18:283-92. doi: 10.1038/ni.3659

168. Frangogiannis NG. Interleukin-1 in cardiac injury, repair, and remodeling: pathophysiologic and translational concepts. Discoveries. (2015) 3:33. doi: $10.15190 / \mathrm{d} .2015 .33$

169. Guillen I, Blanes M, Gomez-Lechon MJ, Castell JV. Cytokine signaling during myocardial infarction: sequential appearance of IL-1 beta and IL-6. Am J Physiol. (1995) 269:R229-235. doi: 10.1152/ajpregu.1995.269. 2.R229

170. Sager HB, Heidt T, Hulsmans M, Dutta P, Courties G, Sebas M, et al. Targeting interleukin-1beta reduces leukocyte production after acute myocardial infarction. Circulation. (2015) 132:1880-90. doi: 10.1161/CIRCULATIONAHA.115.016160

171. Ridker PM, Everett BM, Thuren T, MacFadyen JG, Chang WH, Ballantyne C, et al. Antiinflammatory therapy with canakinumab for atherosclerotic disease. N Engl J Med. (2017) 377:1119-31. doi: 10.1056/NEJMoa17 07914

172. Ridker PM, MacFadyen JG, Thuren T, Everett BM, Libby P, Glynn RJ, et al. Effect of interleukin-1beta inhibition with canakinumab on incident lung cancer in patients with atherosclerosis: exploratory results from a randomised, double-blind, placebo-controlled trial. Lancet. (2017) 390:1833-42. doi: 10.1016/S0140-6736(17)32247-X

173. Gomez D, Baylis RA, Durgin BG, Newman AAC, Alencar GF, Mahan S, et al. Interleukin-1beta has atheroprotective effects in advanced atherosclerotic lesions of mice. Nat Med. (2018) 24:1418-29. doi: 10.1038/s41591-018-0124-5
174. Koelwyn GJ, Corr EM, Erbay E, Moore KJ. Regulation of macrophage immunometabolism in atherosclerosis. Nat Immunol. (2018) 19:526-37. doi: 10.1038/s41590-018-0113-3

175. Ridker PM, Everett BM, Pradhan A, MacFadyen JG, Solomon DH, Zaharris E, et al. Low-dose methotrexate for the prevention of atherosclerotic events. N Engl J Med. (2018) 380:752-62. doi: 10.1056/NEJMoa 1809798

176. Guilliams M, Mildner A, Yona S. Developmental and Functional Heterogeneity of Monocytes. Immunity. (2018) 49:595-613. doi: 10.1016/j.immuni.2018.10.005

177. Zhang H, Xue C, Shah R, Bermingham K, Hinkle CC, Li W, et al. Functional analysis and transcriptomic profiling of iPSC-derived macrophages and their application in modeling Mendelian disease. Circ Res. (2015) 117:17-28. doi: 10.1161/CIRCRESAHA.117.305860

178. Rymer JA, Newby LK. Failure to launch: targeting inflammation in acute coronary syndromes. JACC Basic Trans Sci. (2017) 2:484-97. doi: 10.1016/j.jacbts.2017.07.001

Conflict of Interest Statement: The authors declare that the research was conducted in the absence of any commercial or financial relationships that could be construed as a potential conflict of interest.

Copyright (@ 2019 Zhang, Bories, Lantz, Emmons, Becker, Liu, Abecassis, YvanCharvet and Thorp. This is an open-access article distributed under the terms of the Creative Commons Attribution License (CC BY). The use, distribution or reproduction in other forums is permitted, provided the original author(s) and the copyright owner(s) are credited and that the original publication in this journal is cited, in accordance with accepted academic practice. No use, distribution or reproduction is permitted which does not comply with these terms. 